\title{
Medical expert witness: persistent challenge unexplored
}

\author{
UCP Perera \\ Department of Forensic Medicine, Faculty of Medicine, University of Ruhuna, Galle.
}

Medicine and law are two contrary subjects though both subjects have their ramifications towards each other. Law analyses human behaviour in an objective manner and medicine has relativity of human life as one of its spheres. Both subjects are evidence based but the range of evidence "medicine" relies is far wider. The fundamental tool used in law is "words" and in Medicine is the knowledge based skill. Nowadays doctors are increasingly called to give evidence in courts and its one of the most unfavoured tasks for many of them. Some doctors find themselves uncomfortable in courts and criticize the way they were questioned and the time spent to give evidence. Our attempt here is to evaluate doctor's role in courts and trying to understand the nature of legal argument levelled against medical evidence which is not palatable to medical fraternity most of the time.

It is essential to analyse the role of expert witness in courts before assessing doctor's role. As all medical doctors are often not called upon to give evidence they may loose skills of evidence presentation in courts. Forensic practitioners withstand fierce cross questioning purely because of their extensive experience in court work. It is not mandatory for doctors performing medico-legal work in Sri Lanka to possess legal qualifications. In fact most of them do not have legal qualifications unlike in UK and Australia. What is required for doctors is having a sufficient exposure on the skill and art of giving expert evidence in courts. Unfortunately most of them are not adequately trained on giving evidence at present. They do get an opportunity to listen an expert evidence presentation during undergraduate training or when they are junior doctors.

According to S. 45 of Sri Lankan Evidence Ordinance "When the court has to form an opinion as to foreign law, or of science, or art, or as to identity or genuineness of handwriting or finger impressions, palm impressions or foot impressions, the opinions upon that point of persons specially skilled in such foreign law science or art, or in questions as to identity or genuineness of handwriting or finger impressions, palm impressions or foot impressions, are relevant facts [1]. Such persons are called experts. The S. 45 has some illustrations to clarify the role of expert witnesses and some of these are having medical relevance.

\section{Illustration}

(a) The question is, whether the death of $\mathbf{A}$ was caused by a poison.

The opinion of experts as to the symptoms performed by the poison by which $\mathbf{A}$ is supposed to have died are relevant.

(b) The question is, whether $\mathbf{A}$ at the time of doing a certain act, was, $b$ y reason of unsoundness of mind, incapable of knowing the nature of the act, or that he was doing what was either wrong or contrary to law.

The opinions of experts upon the question whether the symptoms exhibited by A commonly show unsoundness of mind, and whether such unsoundness of mind usually renders persons incapable of knowing the nature of the acts which they do, or of knowing that what they do is either wrong or contrary to law, are relevant.

The subjects referred to in the S. 45 are Foreign Law, Science, Art, Handwriting, Fingerprints, Palm prints \& Foot prints. It has no reference to Medicine or any specialised medical field. The Indian Evidence Act also carries an identical section [2]. The whole medical field is represented as a sub category of "science" which 
is inappropriate according to modern standards. This section is clearly out of date with regard to categorisation of experts and need a major revision. It is the Court that decides as to whether a person is an expert or not. Acquisition of special knowledge need not be the result of professional training. Necessary academic and professional qualifications are not absolutely essential. What the court requires is special skill by reason of practical knowledge and experience. However qualified, knowledgeable and experienced an expert may be, the court is not bound to accept the opinion of an expert. The court may form its independent opinion. Expert opinion is only opinion evidence and is not helpful to the court in interpretation of the law [3].

The Court considers a Medical Officer with MBBS or its equivalent as an expert. However this is limited to give opinions as regards to the ordinary day to day matters. In certain situations the court may hold that a medical officer is not an expert. Given below are two examples.

(a) An inexperienced medical officer doing a complicated autopsy and giving opinions thereon.

(b) Medical Officer expressing opinions in special areas such as ballistics, explosions, surgical procedures, serology etc.

The degree of expertise of a medical doctor varies with the qualifications and the skills possessed by him. A MBBS doctor and specialist doctor in a certain field are treated differently in courts as their level of expertise lie in different strata. The senior doctors should be humble enough to admit mistakes (although not intentional) they have done when they were junior doctors.

\section{Privileges of an expert}

An expert witness is entitled to state facts and express opinions on these facts. An ordinary witness can speak only to facts and cannot give opinions.

The evidence of an expert witness may be in the form of a report like a Post-Mortem Report (PMR) or Medico-Legal Report (MLR) which may be accepted by courts without calling him to testify under Section 414 of the Criminal Procedure Code Act whereas an ordinary witness must testify in court under oath.

In non-summary proceedings an expert witness cannot be summoned to court to give evidence without the consent of the Attorney General under section 148 of the Criminal Procedure code Act.

He is given a special seat in the well of the court and is allowed to remain in court when other ordinary witnesses are giving evidence. He may make arrangements with the Court to be present at a particular time to give evidence.

\section{Bed Head Ticket (BHT)}

Bead Head Ticket is the most important and the preliminary medical document all doctors in Sri Lankan medical institutions are dealing with. However, some of our doctors fail to appreciate that it is the most important legal document in a clinical setting. The majority of BHTT can be of poor quality due to adoption of substandard practices, illegible handwriting, poor recording of facts etc. This is mainly due to minimal attention paid by medical officers to the proper maintenance of a BHT. Any medical officer from a house officer up to consultants of various specialities and medical administrators could be called to give evidence based on BHTT for various reasons. It is very important to enter all details in a BHT with date and time accordingly. Doctors should never attempt or promote the practice of altering facts/comments already recorded in a BHT. They should also remember that obtaining consent of patients for various treatment/procedures on the admission sheet of a BHT is a highly invalid procedure which should be abandoned.

\section{Guidelines to be an effective medical expert witness}

Medical Evidence presentation in courts is a verbal battle. It starts smoothly when prosecution testifies your evidence and gets heated up when defense counsel starts cross examination. 
Lawyers have a different stance. Some are aggressive and some are soft spoken. Doctors are usually soft spoken in courts. It is our experience that most doctors other than full time JMOO are incapable of handling their mother tongue, Sinhala when giving evidence.

Language fluency is an essential factor for good evidence presentation as tactful lawyers always bisect your words and go deep into the meaning. In Sri Lankan set up most medico-legal reports and PM reports are written in English and expert evidence is obtained in Sinhala or Tamil. Doctors feel more comfortable when they use English to describe medical points rather than their own language. Due to this fact they can be trapped when explaining difficult medical terms or procedure in courts. The best possible way to overcome this difficulty is to go through his report before the trial with a colleague used to court work.

\section{(1) Respect the Court of Law}

(a) Obey summons either to attend Court of Law or to send a report. Inability to do so should be informed promptly to court giving reasons.

(b) Be punctual. If getting late inform Court of Law, for court will accede to your request as they are aware that medical officers are quite busy.

(c) Be properly clad. The males must wear a coat \& tie and the females a saree.

(d) Never leave court without informing relevant authorities or obtaining permission from them.

(2) Be polite to the Judge, prosecuting counsel, defence counsel and other court officials.

(3) Never lose your temper however much you may be provoked, especially by the defence in cross examination. Always be calm. Appeal to the Judge if personal matters irrelevant to the case are raised by the counsel. The moment you loose your temper you are on the verge of making misrepresentation of facts. Remember that you are involved in a verbal battle. Good defence lawyers are usually better equipped with words and waiting there for you to make a mistake. Be very careful when you are giving affirmative answers. Use your words carefully as all verbal arguments are recorded.

(4) Always remember that you are a witness of court and not a witness of either the prosecution or the defence who may have called you as a witness.

Your duty is to assist court to find the truth. Therefore give independent, impartial \& truthful evidence. The outcome of the trial should not be your concern. Remember that you are not battling out your own case. It is applicable even when you are called upon to give expert evidence in medical malpractice litigation involving your colleagues in medical profession. This may be a very difficult attitude to perceive at the initial stages of your carrier. Amedical expert witness plays an essential role in determining medical negligence [4]. It may be advisable to avoid being an expert witness against one of your colleagues working in the same hospital.

(5) Should possess sufficient skill and knowledge according to your qualifications and experience.

(6) Should know the limitations, pit falls and short comings in your skill and knowledge and be ready to admit them.

(7) Evidence should be logical, clear, reasonable, complete and in a language understood by Court. Avoid technical terms as much as possible. Fluency in native languages is very important as all primary and many secondary courts use official languages in Sri Lanka.

(8) Be ready with your documents like notes, reports, charts, diagrams and illustrations. The Court may need to peruse them.

(9) Support your opinions with experience, publications and text books. It is a good practice to take photocopies of the material you are expected to quote to the courts as 
the opposite counsel and perhaps the judge may ask for copies of it.

(10) It is a good practice to discuss your case report with your colleagues in an open forum before going to courts. Their constructive criticisms may be helpful for you to clear the grey areas and to further the insight into the case. Never hesitate to discuss with your colleagues. Court cases are not personal issues and your evidence becomes a public statement soon after you step into the witness box. Lack of peer reviewing is one of the major deficiencies encountered by our medical testimonies.

(11) If you contradict another expert, always justify it with any special knowledge, research, experience, publications, texts etc. Do not state any personal issues. If you need more time to quote the extracts ask for another date.

(12) Be firm in your convictions. Never give evasive answers or sway from side to side to suggestions put to you by either party to support their cause in examination in chief, cross examination or re-examination.

(13) If you do not know the answer to a question put to you always say that you do not know the answer and never give a false answer. It is more important to maintain your professional integrity rather than battling out individual situations.
(14) Never stray into fields in which you are not an expert. You may step into sub fields of your discipline unintentionally when giving evidence or a tactful counsel may drag you to an outside area beyond your expertise. It is a good practise to have a pre-evaluation about the limitations of your evidence on the previous day.

(15) Giving evidence in courts always requires extreme tolerance. You will invariably waste important time at courts due to procedural matters and it is a universal experience. Take few reading material with you which may or may not be related to the subject matter.

Giving medical expert evidence in courts is a skill as well as an art. A skill could be developed; an art should be derived by your own experience. Enjoy giving evidence in courts. Your evidence matters always.

\section{References}

1. Legislative Enactments of Sri Lanka: Evidence Ordinance, 1895 ; No. $14: 45$.

2. Indian Evidence Act, 1872; 45.

3. Ratanlal and Dhirajlal's The Law of Evidence. $19^{\text {th }}$ edition 1999; 195.

4. American Academy of Paediatrics policy statement Paediatrics. May 2002;109(5); 974-9. 